\title{
As mulheres na produção editorial científica ilustrada do século XIX: Maria Graham, Anna Atkins e Matilda Smith*
}

\author{
Maria de Fátima Medeiros de Souza** \\ Emerson Dionisio Gomes de Oliveira***
}

\begin{abstract}
Resumo
Ao longo do século XIX, houve mudanças marcantes na produção científica ilustrada, e a participação das mulheres nesse gênero editorial ocorreu de diferentes modos. Muitas mulheres contribuíram ativamente com as pesquisas científicas. Eram coletoras de plantas, artistas viajantes que percorreram lugares distantes, ilustradoras que estudaram os rígidos postulados da produção científica e que, muitas vezes, exploraram novos métodos de produção de imagens para livros de história natural. Aqui trataremos de três artistas britânicas, Maria Graham, Anna Atkins e Matilda Smith, que viveram em períodos distintos do século XIX e que colaboraram com a produção científica ilustrada alcançando postos de trabalho em periódicos renomados e publicando livros para tradicionais casas editoriais do período.
\end{abstract}

Palavras-chave: Maria Graham, Anna Atkins, Matilda Smith, Produção Científica Ilustrada.

\footnotetext{
* Recebido em 03 de junho de 2019, aceito em 19 de maio de 2021.

** Docente voluntária do curso de Teoria, Crítica e História da Arte da Universidade de Brasília; servidora pública da Secretaria de Cultura do Distrito Federal, Brasília, DF, Brasil. medeiros fatima@ hotmail.com / http://orcid.org/0000-0003$\underline{0176-5286}$

***Docente e pesquisador do Departamento de Artes Visuais no Programa de Pós-graduação em Artes Visuais e no Programa de Ciência da Informação da Universidade de Brasília, Brasília, DF, Brasil. Pesquisador do Conselho Nacional de Desenvolvimento Científico e Tecnológico - CNPq. dionisio@unb.br / http://orcid.org/0000-0002-3705-1667
} 
Women in Illustrated Scientific Publishing of the 19th Century: Maria Graham, Anna Atkins And Matilda Smith

\begin{abstract}
Significant changes occurred in scientific illustration and women participated in them in a variety of ways. Many women have actively contributed to scientific research. They were plant collectors, artists who traveled through distant lands and illustrators who studied the strict postulates of science and often explored new methods for producing images for natural history books. In this paper we examine three English artists, Maria Graham, Anna Atkins, and Matilda Smith, who lived in different periods of the 19th century and were employed at renowned journals and publishing houses.
\end{abstract}

Keywords: Maria Graham, Anna Atkins, Matilda Smith, Illustrated Scientific Production. 


\section{Introdução}

A história das mulheres na ciência é marcada por ocultações, silêncios e novas descobertas. Se olharmos para as mudanças nos costumes observadas em um passado próximo, perceberemos o quanto é essencial estarmos constantemente atentas aos apagamentos. Este artigo trata de três mulheres que viveram no século XIX e que construíram suas carreiras na ciência $e$ na arte, publicando, pesquisando e divulgando os avanços nos métodos empíricos e na representação da natureza. As mulheres tiveram um papel fundamental na história da ciência, e isso pode ser comprovado pelos documentos e acervos coletados pelas viajantes, que hoje estão guardados em instituições como o British Museum e o Royal Botanic Gardens (KEW Gardens). Além disso, a participação consistente em publicações científicas ilustradas comprova a relevância dessas artistas e cientistas. Essa ainda é uma história que precisa ser contada, dada a escassez de pesquisas sobre o tema e porque é crucial em nosso tempo refletir sobre esses apagamentos e esquecimentos em relação à participação das mulheres em diversos aspectos de nossa sociedade.

Como destaca Betty Hagglund (2011), as lições de botânica eram essenciais para as jovens inglesas de classe média do século XIX. Para muitas mulheres, o contato com a botânica não estava restrito ao diletantismo, muitas viajaram para locais distantes, pesquisaram e publicaram suas ilustrações e notações botânicas em periódicos proeminentes. Trataremos da participação das mulheres na produção botânica ilustrada do século XIX a partir das obras de Maria Graham (17851842), Anna Atkins (1799-1871) e Matilda Smith (1854-1926).

A dificuldade ou impossibilidades de acesso às instituições, universidades e sociedades botânicas fez com que as mulheres buscassem outras formas de inserção na produção científica. As redes de sociabilidade estabelecidas nas casas de mulheres e de homens da alta classe na Inglaterra constituíam um dos meios de atuação. No século XVIII, havia estruturas ativas nos espaços domésticos, construídas em torno das instituições científicas. A produção acadêmica estava intrinsecamente associada a esses centros de sociabilidade que, em muitos casos, eram providos de laboratórios com equipamentos avançados, bibliotecas de referência, registros visuais e coleções naturais. Esses aparatos foram essenciais para a inserção das mulheres nas ciências e contribuíam para que elas traçassem suas redes de relações com outros naturalistas do período (Schienbinger, 1991; Palmer, 2019; 2015; Souza, 2020).

As produções das três artistas e cientistas selecionadas para este estudo estão situadas ao longo do século XIX, Graham e Atkins na primeira metade dos oitocentos e Smith nas últimas décadas. Esse espaço temporal permite identificar mudanças nos modos de reprodução das imagens e na participação das mulheres nas sociedades botânicas e na publicação de livros científicos.

\section{Notações sobre a flora e os costumes: Maria Graham e a literatura de viagem}

Maria Graham foi uma escritora e artista viajante que percorreu países como Índia, Brasil, Chile, Itália, Alemanha e Áustria durante a primeira metade do século XIX. Sua produção visual pode ser dividida em dois principais eixos: o primeiro abarca os cadernos de viagem com registros visuais associados aos diários de viagem e o segundo eixo contempla as ilustrações botânicas. Até o momento, as obras mais significativas dessa artista viajante estão em Londres, no British Museum e no Kew Gardens. No Brasil, algumas obras atribuídas à Graham estão na Biblioteca Nacional, no Centro Cultural São Paulo e no Museu de Arte de São Paulo (Souza, 2017; 2020; Filgueiras; Peixoto, 2008).

As mulheres que participavam das viagens científicas, em geral, eram casadas com diplomatas em missões no exterior ou colonas estabelecidas fora da Europa. Evidentemente, essas condições facilitaram o trânsito dessas mulheres por locais distantes e o trabalho profissional e amador com a botânica, tudo isso em um contexto de plena ascensão da edição de livros de história natural voltados especificamente para instrução das mulheres. Maria Graham também aproveitou as oportunidades ensejadas pelas suas relações pessoais para viajar para diversos países, pois seu pai $e$ 
seu primeiro marido trabalharam para a Marinha Britânica ${ }^{1}$ (Hagglund, 2011; Thompson, 2017, 2015, 2012).

A literatura de viagem foi um dos principais interesses de Maria Graham. No final de 1808, Graham partiu para a Índia, viagem que resultou na publicação de seus dois primeiros livros, editados pela Constable \& Longmañ2. Após o sucesso editorial dessas publicações, Graham escreveu os diários de viagem ao Brasil e ao Chile, ambos editados pela John Murray Press, em 1824 (Graham, 1824a;1824b). Embora Graham possua uma vasta produção visual, poucos estudos se dedicaram a pesquisar esse aspecto de sua carreira. Tratar das imagens produzidas por essa viajante a partir da perspectiva da produção editorial ilustrada pode contribuir para os estudos das obras dos artistas viajantes como um todo, pois parte significativa das imagens produzidas por esses profissionais e amadores estava associada às publicações.

$\mathrm{Na}$ primeira metade do século XIX, momento em que Graham publicou seus livros, a literatura de viagem conjugava, entre outros aspectos, a história natural, a botânica, a cartografia e notas sobre os costumes das localidades visitadas. De certo modo, era esperado que os viajantes conjugassem em seus diários essas informações para que suas narrativas alcançassem validade no meio editorial. No caso de Graham, ela foi educada por uma tutora que a incentivou a estudar as plantas, um interesse que iria perdurar por toda a sua produção visual e editorial. Após essa primeira formação, Graham passou uma temporada na Universidade de Edimburgo, onde conheceu Dugald Stewart ${ }^{3}$ (1753-1828) e John Playfair ${ }^{4}$ (1748-1819), figuras eminentes do iluminismo escocês que admiraram a sagacidade e a dedicação de Graham (Hagglund, 2011; Stephen, 1886; Thompson, 2012).

Ao longo da carreira, Graham se correspondeu com intelectuais, colecionadores, artistas e naturalistas. A viajante era tida como uma hábil informante por figuras como John Murray II (17781843), editor da John Murray Press, William Hooker (1785-1865), naturalista e diretor do Kew Gardens, e Sir Thomas Lawrence (1769-1830), artista e diretor da Royal Academy of Arts. Na primeira metade do século XIX, essas colaborações foram essenciais para a formação intelectual e para a carreira das mulheres, uma vez que elas dependiam de locais às margens das grandes instituições para se especializar nas áreas científicas. Nesses espaços, a sociedade erudita se reunia para discutir suas últimas pesquisas, trocar coleções naturais e imagens relacionadas às viagens, entre outras práticas (Thompson, 2017; Palmer, 2015, 2019; Schiebinger, 1991).

Grande parte dos diários de viagem de Maria Graham foi ilustrada com gravuras a partir de seus desenhos. Alguns diários de viagem, como é o caso dos referentes à passagem por Roma, foram ilustrados a partir dos desenhos de Charles Eastlake (1793-1865), artista que acompanhou a viajante em outros percursos e que atuou em parceria com outros viajantes. Graham também trabalhou com os gravadores Auguste Earle (1793-1838) e Edward Finden (1791-1857), prática comum nas publicações ilustradas do período. Finden, por exemplo, trabalhou para a John Murray Press como gravador, entre 1820 e 1830, sendo responsável pela confecção das estampas dos livros

\footnotetext{
1 Maria Graham era filha de Ann Thompson (?-c.1793) e George Dundas (1756-1814), oficial da marinha britânica. Seu nome de solteira era Maria Dundas e, após se casar com o capitão da marinha britânica, Thomas Graham (?-1822), ela passou a se chamar Maria Graham. Thomas morreu durante a viagem de navio que seguia do Brasil para o Chile, em 1822. Após cinco anos, em 1827, Graham se casou com o pintor Lord Augustus Wall Callcott (1779-1844), passando a se chamar Maria Callcott (ou Lady Callcott) (Akel, 2009).

2 Journal of a Residence in India (1812) e Letters on India (1814).

3 Foi um filósofo escocês, e suas principais obras são: Elements of the Philosophy of the Human Mind, 3 vol. (1792, 1814 e 1827), Outlines of Moral Philosophy (1793), Philosophical Essays (1810) e Philosophy of the Active and Moral Powers of Man (1828), cf. Encyclopaedia Britannica [https://www.britannica.com/biography/Dugald-Stewart - acesso em: 09 fev. 2019].

4 Geólogo e matemático escocês, Playfair foi professor de filosofia natural na Universidade de Edimburgo. Suas principais obras são: Elements of Geometry (1795), Illustrations of the Huttonian Theory of the Earth (1802) e Outlines of Natural Philosophy (1812-16), cf. Encyclopaedia Britannica [https:/www.britannica.com/biography/John-Playfair-Scottishgeologist-and-mathematician - acesso em: 09 fev. 2019].
} 
dos viajantes que publicaram pela editora. Além dos livros de viagem de Maria Graham pela América do Sul ${ }^{5}$, Finden gravou estampas de outras narrativas de viagem por esse subcontinente ${ }^{6}$.

A Gameleira, árvore retratada na obra Tree in a Garden at Bahia, foi uma das imagens gravadas por Finden para o diário de viagem de Graham ao Brasil. Ao observar o desenho da viajante ao lado da estampa, percebemos as mudanças operadas por Finden para a adequação da obra à linguagem da gravura. Detalhes da Gameleira, como as plantas parasitas que crescem nos troncos, estão mais evidentes no desenho, enquanto a gravura destaca os contrastes entre os planos e realça a atmosfera geral na composição (Figuras 1 e 2) (Bell; Keighren; Withers, 2015; Souza, 2020).

Figuras 1 e 2. GRAHAM, Maria. Tree in a Garden at Bahia. Pen and black ink, 1824; FINDEN, Edward. Tree in a Garden at Bahia. Gravura em metal, 1824.
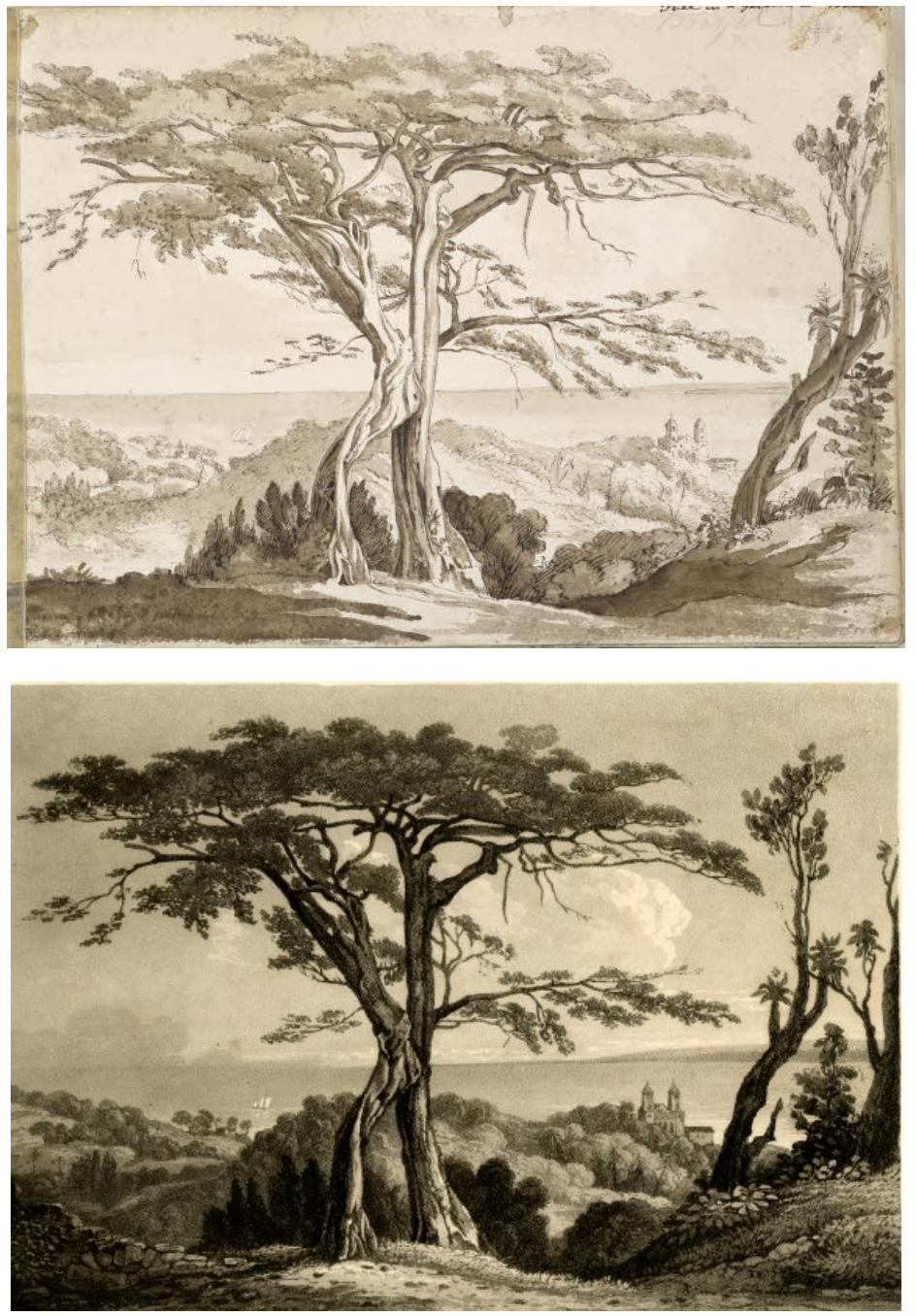

Fonte: Cortesia do Museu Britânico.

Paralelamente à escrita, Maria Graham costumava a fazer registros detalhados de seus percursos em cadernos de viagem. Exemplos disso são os dois álbuns que estão guardados no acervo do Museu Britânico. Um dos álbuns é formado por registros das passagens de Graham pela Índia, Itália, Ilha da Madeira, Sri Lanka, África do Sul e Inglaterra. O outro álbum contém 143

\footnotetext{
5 Journal of a voyage to Brazil and a residence there during part of the years 1821, 1822, and 1823 (1824) e Journal of a Residence in Chileournal of a voyage to Brazil and a residence there during part of the years 1821, 1822, and 1823 (1824), ambos publicados em 1824.

${ }^{6}$ Caso do livro Travels through the interior provinces of Columbia, de John Potter Hamilton, editado em 1827 (Bell; Keighren; Withers, 2015).
} 
desenhos, produzidos durante o percurso da viajante pela América do Sul, e abrange, majoritariamente, registros de plantas e de paisagens ${ }^{7}$. É importante ressaltar que o predomínio dos registros da natureza tropical pode ser associado ao interesse do público britânico por esse tipo de paisagem (The British Museum, 2019; Thompson, 2015; Bell; Keighren; Withers, 2015).

O principal tema da produção visual de Maria Graham é a paisagem. Bastante difundidas entre o público britânico por meio de gravuras e livros como $A$ Guide to the Lakes (1778), de Thomas West (1720-1779), e Three essays of picturesque beauty, de William Gilpin (1724-1804), as imagens pitorescas traziam representações topográficas e destacavam as particularidades da flora, suas texturas, formas, luzes, linhas. Esses recursos visuais eram usados para dar à paisagem uma riqueza a partir da diversidade da natureza.

Como se nota a partir das obras de Graham, as imagens também eram recursos usados para mapear o espaço. Na representação da Gameleira, a artista apresentou a árvore destacada em primeiro plano e descreveu as suas principais características. Nos planos subsequentes, observamos uma paisagem com uma igreja, no estilo barroco, entre as montanhas, seguida da vista do mar, ao fundo da composição. Interessa à viajante britânica mostrar que a árvore foi encontrada em um jardim nas cercanias da Bahia. Nesse sentido, os elementos característicos da paisagem e da arquitetura evocam a noção de deslocamento (Figuras 1 e 2).

Maria Graham também registrou as cercanias do Rio de Janeiro. São imagens que retratam a sua casa no Bairro de Laranjeiras e o Jardim próximo do Morro do Corcovado. Seguindo uma tendência de publicações destinadas a mapear paisagens naturais como montanhas, lagos $e$ florestas do Reino Unido, artistas britânicos se voltavam para a paisagem do Brasil com uma visão estética do arcadismo. Nessas obras, também é possível identificar uma noção de pitoresco associada à representação detalhada da natureza ou mesmo da representação de cenas com temáticas campestres e bucólicas. A diversidade da natureza nas obras de Graham articula questões relacionadas à representação naturalista e algumas acepções de pitoresco (Figuras 3 e 4).

Outras ilustrações do diário de viagem de Graham ao Brasil evidenciam sua aproximação com os postulados de Alexander von Humboldt (1769-1859). Essa afiliação pode ser identificada pela disseminação de modelos para a representação da natureza que enfatizavam as tipologias de árvores, as diferentes folhagens e cores das matas tropicais. Representações como a da árvore do dragão em Tenerife, que ilustra o diário de viagem ao Brasil, testemunham as referências de Graham aos escritos do renomado viajante. Para a estética de Humboldt, as pinturas do século XVII do norte da Europa eram modelos para a pintura de paisagem, pois representavam a natureza de modo descritivo e menos idealizado se comparadas com as paisagens da escola italiana. De modo geral, Graham articulava os métodos descritivos da paisagem holandesa com elementos da paisagem clássica difundida por Claude Lorrain (1600-1682) e Gaspar Dughet (1615-1675) (Mattos, 2004; 2008; Souza, 2020).

\footnotetext{
7 Esses álbuns, provavelmente, foram organizados pelo segundo marido de Maria Graham, Augustus Wall Callcott e, posteriormente, doados ao Museu Britânico, em 1844 (The British Museum, 2019).
} 
Figuras 3 e 4. GRAHAM, Maria. Part of the Lagoa near Rio do Janeiro, s/d; Signor Padre Manoel Gomez Vigario do este Lugar N Sra da Cabeca, s/d. Brown wash with pen, respectivamente.
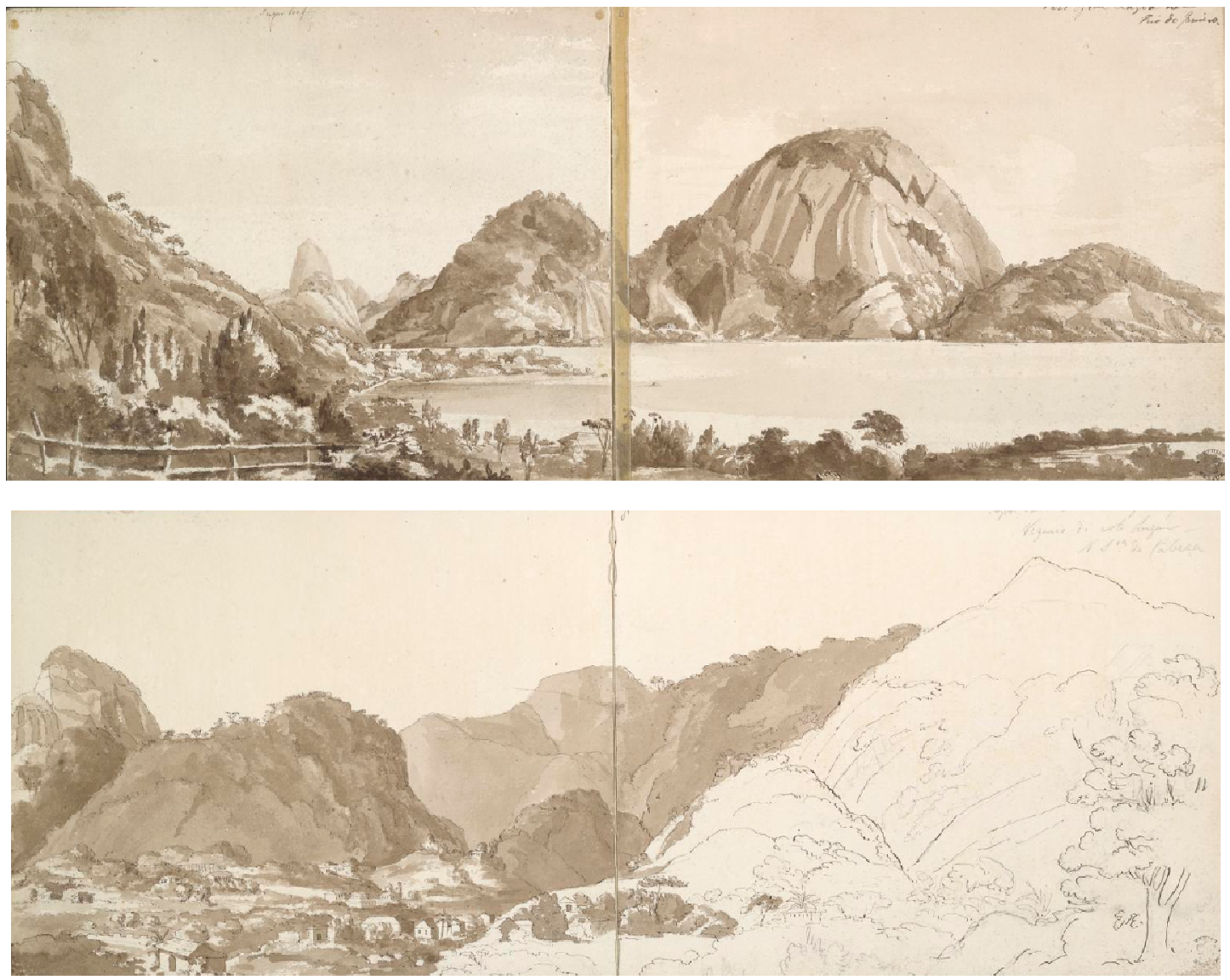

Fonte: The British Museum, Prints \& Drawings, 2019.

A literatura de viagem se prestava tanto para entreter quanto para instruir, na medida em que alcançava o público leigo e especializado. Assim, tanto a escrita quanto a imagem deveriam descrever minuciosamente os fenômenos observados, tal como propunha o modelo de registro visual difundido por Humboldt. Desse modo, é possível identificar nas imagens de Graham um rigor descritivo perceptível na atenção dispensada às plantas, na representação dos diferentes formatos das folhas e dos troncos, assim como na tentativa de representar com maior exatidão as copas das árvores (Bell; Keighren; Withers, 2015; Graham, 1824; Rodenas, 2014).

A editora John Murray Press foi uma das mais destacadas casas editoriais a publicar livros de viagem durante o final do século XVIII e a primeira metade do século XIX. O perfil dos autores que publicaram por essa editora é formado, majoritariamente, por homens britânicos de classe alta, muitos dos quais em missão diplomática a serviço da marinha britânica ou que trabalhavam para o comércio exterior britânico. Uma pequena parcela de autores era formada por mulheres: "apenas trinta escritoras, entre 1773 e 1859, eram mulheres, Maria Graham destacou-se como uma exceção nesse pequeno grupo como autora e editora de três publicações" (Bell; Keighren; Withers, 2015:25, tradução nossa). Outra autora que teve um livro publicado pela John Murray foi Sarah Lushington (1789-1839). Nascida na Índia e filha de colonos ingleses, Lushington trabalhou como secretária do governo de Bengala e se interessou pelas viagens exploratórias. O livro Narrative of a Journey from Calcutta to Europe, by Way of Egypt, in the Years 1827 and 1828 foi editado duas vezes em 1829, tamanho o sucesso de vendas. O livro trata da longa viagem da autora, que saiu da Índia rumo à Europa tomando o caminho do Mar Vermelho e atravessando o deserto do Egito (British Travel Writing, 2019).

Para algumas autoras de literatura de viagem, como a francesa Flora Tristan (1803-1844), a escrita era uma possibilidade de reivindicar espaços restritos aos homens, tanto em relação ao papel 
das mulheres na vida pública, quanto no que se refere à escrita literária e jornalística. Considerada como filha ilegítima de um peruano, Flora Tristan viajou para o Peru logo após seu conturbado divórcio. A respeito de Tristan, Rodenas (2014:4) destaca:

Fingindo ser solteira, a fim de evitar o estigma associado às mulheres separadas de seus maridos, Tristan examinou, com uma perspectiva incisiva e crítica, posto que enviesada, o mapa do Peru e Lima regionais. Quando de seu retorno à Europa, a peregrinação de Tristan pelo novo mundo a levou a adotar conscientemente o papel de redenção para a classe trabalhadora Europeia (Rodenas, 2014:4, tradução nossa) ${ }^{8}$.

No caso de Tristan, escrever também era um ato eminentemente político, no qual se nota a preocupação em evidenciar a condição das mulheres em uma sociedade misógina. Além disso, temas como a escravidão $e$ as injustiças sociais foram frequentemente debatidos em seus escritos. No contexto francês da primeira metade do século XIX, muitas mulheres e homens divulgaram seus ideais feministas em periódicos de grande circulação. Tristan publicou tanto literatura de viagem, caso de Pérégrinations d'une paria, editado em 1833-34, como artigos para jornais e folhetins franceses (Amarante, 2010).

Maria Graham, embora não tenha se ocupado explicitamente com questões relativas às causas das mulheres, tratou da condição feminina em ambientes eminentemente masculinos e, mais largamente, descreveu os costumes das mulheres dos países que visitou. No diário de viagem ao Brasil, ela narrou que foi recebida nas casas de outras mulheres nobres e de classe alta e descreveu grupos femininos observados no Rio de Janeiro, em Pernambuco e na Bahia. As mulheres que estavam no Brasil nesse período eram, em grande parte, brasileiras e portuguesas brancas, negras escravizadas e libertas, índias e mestiças. Os relatos de Graham tratam da forma como as mulheres se vestiam e se portavam, sendo comum encontrarmos algumas críticas, caso do excerto abaixo:

Quando apareciam, dificilmente poder-se-ia acreditar que a metade delas eram senhoras de sociedade. Como não usam nem coletes, nem espartilhos, o corpo torna-se quase indecentemente desalinhado, logo após a primeira juventude; e isto é tão mais repugnante quanto elas se vestem de modo muito ligeiro, não usam lenços ao pescoço $e$ raramente os vestidos têm qualquer manga. Depois, neste clima quente, é desagradável ver escuros algodóes e outros tecidos, sem roupa branca, diretamente sobre a pele, o cabelo preto mal penteado $e$ desgrenhado, amarrado inconvenientemente, ou, ainda pior, em papelotes, $e$ a pessoa toda com a aparência de não ter tomado banho (Graham, 1956:168).

O fragmento se refere a uma ocasião em que Graham esteve na casa de uma família portuguesa de classe alta. Além de tratar da forma com que as mulheres se vestiam e se portavam em ambientes privados, a narrativa menciona particularidades da habitação, com descrição dos objetos e da aparência geral do local. Como já afirmado, os livros de viagem retratavam, ao mesmo tempo, a experiência individual e a documentação dos povos das localidades visitadas.

Os relatos de Graham se constituíram, muitas vezes, a partir da comparação com os costumes $e$ os modos do povo britânico, por isso é comum encontrar críticas à maneira "desleixada" e "preguiçosa" das portuguesas. Gonçalves (2005) enfatiza que a matriz luso-brasileira partia de noções de espaços público e privado diferentes das encontradas em outros países europeus. Em Portugal, as esferas pública e privada eram mais próximas, o espaço da convivência familiar se misturava com o das ruas, de maneira que essa dimensão íntima do espaço público resultou em certa "falta de compostura" dos portugueses, segundo os relatos dos escritores viajantes desse período:

Nas narrativas de viajantes os costumes não só brasileiros como portugueses manifestam a ausência de decoro corporal. O viver luso-brasileiro realçava sem cessar um estilo de vida que pareceu remoto ao cotidiano desses andarilhos do mundo. Nessa acepção, a exibição de partes

\footnotetext{
8 "Feigning to be single in order to avoid the stigma attached to women separated from their husbands, Tristan surveyed the map of regional Peru and Lima with an incisive, if often tainted, critical perspective. Upon her return to Europe, Tristan's New Word pilgrimage ultimately led her to consciously adopt the role of redemptions for the European working class" (Rodenas, 2014:4).
} 
do corpo, que as maneiras do código civilizado impunham que fossem cobertas, produziu sempre mal-estar e embaraço. Os corpos desnudos ou mesmo encobertos por inúmeros panos indicavam sem cessar o excesso.

[...]

Entre viajantes desponta uma modelagem de subjetividade centrada na auto reflexividade e na interiorização, em que o domínio sobre si está associado a uma moral do corpo que implica sentimentos de pudor; a sua exposição restringe-se à mais recôndita intimidade. Assim, a ausência de mecanismos de controle na exibição do corpo transforma brasileiros e portugueses em "quase bárbaros" (Gonçalves, 2005:620).

John Luccock (1770-1826), escritor viajante britânico que esteve no Brasil no século XIX, identificou, na postura das colonas portuguesas, o uso de alguns recursos para espreitar a vida alheia. O constante uso de véus em espaços públicos e até mesmo o tipo de janela em treliça das casas portuguesas durante o período colonial seriam alguns dos meios usados para "bisbilhotar". Muitos dos escritos dos viajantes que relataram os costumes das mulheres luso-brasileiras partiam da noção de que os hábitos displicentes com o corpo indicavam falta de decência e de moral.

Descrições sobre os costumes das mulheres também foram tratados por Graham em seus dois livros sobre a Índia. Os relatos mencionam religião, rituais fúnebres, poligamia, divisão social por castas, entre outros aspectos. As indumentárias das mulheres indianas ocupam parte das descrições de Graham, que relata a forma com que os imensos tecidos de seda eram amarrados ao redor do corpo, o uso de turbantes e a profusão de joias e adereços que adornavam a figura feminina. Também encontramos menção à forma com que as indianas arranjavam seus negros cabelos $e$ relatos sobre o porte elegante das mulheres. No que diz respeito às relações de trabalho, Graham afirma que as indianas ocupavam cargos semelhantes aos dos homens de suas castas. Inclusive, elas realizavam certos serviços braçais, como carregar grandes cargas ou mesmo preparar o solo para o cultivo (Graham, 1814).

Embora produzam julgamentos moralizantes, típicos de uma viajante britânica do período, alguns dos relatos de Graham em terras estrangeiras adotam uma linguagem didática e descritiva. Certas narrativas sobre os costumes da população indiana também não demonstram sensação de estranhamento. A viajante costumava comparar rituais do povo indiano com práticas difundidas entre os europeus. Esse método comparativo e o cruzamento de dados com diversas fontes foi largamente adotado em narrativas de viagem do período e denotava a erudição das escritoras.

Para escrever com propriedade, Graham procurava observar os rituais e explorar particularidades das localidades que seriam descritas em seus diários. Além disso, ela pesquisava em bibliotecas particulares, se preparava antes de viajar, estudando sobre a história dos países que iria visitar, e interagia com a população local. Gonçalves (2011) ressalta, no diário de Graham à Índia, modulações de uma erudita que combina relatos de costumes e narrativas de caráter pessoal aos moldes da literatura de viagem dos oitocentos:

A crescente ênfase na vida privada, tanto na dimensão social, quanto da intimidade da casa, corrente em publicações de gêneros variados, mostra um painel que afrouxa as fronteiras entre gêneros tão diversos como história dos costumes, história literária, história religiosa, biografia, memória, romance, literatura de viagem, pesquisa antiquária (Gonçalves, 2011:100).

As produções escrita, visual e botânica de Graham transitaram em espaços majoritariamente ocupados por homens. As mulheres viajantes romperam algumas barreiras sociais, uma vez que a própria viagem de navio podia apresentar perigos para aquelas que estivessem desacompanhadas, já que a presença de mulheres na embarcação era rara. Além disso, o acesso às informações sobre assuntos relacionados à política e economia, em muitos momentos, era dificultado ou barrado a essas escritoras. No diário de viagem ao Brasil, Maria Graham relatou a dificuldade que enfrentou em razão de seu gênero: "Minhas oportunidades de informação foram muito raras. Meus hábitos, como mulher e estrangeira, nunca me conduziram a situações onde pudesse adquirir o necessário conhecimento" (Graham, 1956:65). 
Mesmo frente às adversidades, a recepção da obra literária e científica de Graham é notória. A viajante trocou correspondências com William Hooker e essa parceria baseou-se em um respeito mútuo, sem que o naturalista fizesse distinção entre os serviços prestados por coletores e coletoras espalhados pelos continentes. Durante uma das viagens de Graham pelo Brasil, ela se dedicou à ilustração da flora, e Hooker costumava enviar instruções para coleta, registro e envio de plantas. $\mathrm{O}$ acervo resultante das pesquisas de Graham está no Kew Gardens (Souza, 2020; Filgueiras; Peixoto, 2008).

As publicações de Graham na área da botânica alcançaram notoriedade. Seu livro, $A$ Scripture Herbal, foi o único volume escrito por uma mulher a aparecer na lista da Sociedade Real Médica e Cirúrgica de Londres. No Brasil, Graham colaborou com a expedição de Georg von Langsdorff (1774-1852) como coletora de espécimes, função que ela também desempenhou para a obra Flora Brasiliensis, de Carl von Martius (1794-1868) ${ }^{9}$. Além da contribuição científica, a narrativa de Maria Graham se destaca entre os principais relatos de viagens de seu período no contexto britânico.

\section{Cyanotype Impressions: os processos fotográficos e a reprodução das imagens científicas}

Ao longo do século XIX, ocorreram mudanças significativas na produção das imagens científicas. Uma delas, talvez das mais profundas operadas na representação visual, foi a invenção da fotografia. Na verdade, como dizem Daston e Galison (2007:125, tradução nossa), "a fotografia não foi apenas uma, mas várias invenções" que, entre outros usos, serviram para alcançar efeitos $e$ para estudar fenômenos visuais. A produção de imagens destinadas ao registro da história natural, especialmente a partir da segunda metade do século XVIII, era acompanhada de perto pelos cientistas. Essa prática contribuiu para a aceitação da imagem como um modo de produção de conhecimento, uma vez que naturalistas supervisionavam todo o processo para identificar na representação qualquer traço de "inventividade" ou de "desvio" da natureza praticado pelo artista. Nesse sentido, a introdução dos métodos mecânicos trouxe maior credibilidade à representação visual dos fenômenos, embora seja necessário notar que não havia uma confiança irrestrita nesses métodos:

Máquinas não funcionavam sozinhas, é claro. Durante todo o século XIX, cientistas trabalharam com especialistas em fotografia microscópica, gravura ou ilustração botânica e anatômica. Porém, enquanto os eruditos do século XVIII tentavam impor suas vontades e pontos de vista sobre tais ajudantes-colaboradores, a fim de atingir uma visão a "quatro olhos", no século XIX, essa relação passava por uma mudança dramática. De um lado, o autor do século XIX falava incessantemente em "policiar" o ilustrador. De outro, o cientista dependia do ilustrador para frear os voos de fantasia e especulações do autor (Daston; Galison, 2007:123, tradução nossa) ${ }^{10}$.

A botânica e fotógrafa Anna Atkins se notabilizou como uma das pioneiras na produção científica ilustrada com fotografias. A obra British Algae: Cyanotype Impressions foi editada em 1843 e apresenta uma série de ilustrações feitas com a cianotipia, técnica de cópia fotográfica descoberta por Sir John Herschel (1792-1871), na qual as imagens são formadas a partir de tons de azul, utilizando sais de ferro como substâncias fotossensíveis. Com uma tiragem limitada a vinte e cinco cópias, o livro de Atkins figura em coleções de museus como as do Getty Museum e do Natural History Museum, por exemplo. A obra também evidencia o papel dos novos modos de registro da natureza, a partir dos experimentos com as técnicas fotográficas (Getty Museum, 2018; Natural History Museum, 2019).

\footnotetext{
9 Graham e a Princesa Teresa da Baviera (1850-1925) foram as únicas mulheres a participar desse monumental empreendimento botânico (Filgueira; Peixoto, 2008).

10 "Machines did not run themselves, of course. All through the nineteenth century, scientists worked with experts on microscopic photography, engraving, or botanical and anatomical illustration. But whereas eighteenth-century savants had sought to impose their will and way of seeing on such helper-collaborators to achieve four-eyed-sight, by the nineteenth century this relationship was undergoing in the dramatic change. On the one side, the nineteenth-century author spoke incessantly of "policing" the illustrator. On the other, the scientist relied on the Illustrator to check the author's flights of fancy and speculation" (Daston; Galison, 2007:123).
} 
A cianotipia foi uma técnica muito difundida no período devido à sua facilidade de produção e baixo custo. No processo de produção de seu livro, Anna Atkins coletava as algas, secava-as, para, então, colocá-las sobre folhas de papel com uma substância fotossensível (entre 10 e 40 minutos, aproximadamente). Em seguida, esses papéis eram lavados e expostos à luz do sol. $\mathrm{O}$ resultado são imagens em negativo que revelam as estruturas delicadas das espécies, além de um efeito que sugere a impressão de um espectro da planta sobre o papel. Esse efeito pode ser observado nas Figuras 5 e 6, que mostra uma das 389 espécies de algas registradas por Atkins. A produção das 25 cópias do livro durou mais de dez anos, totalizando quase dez mil cópias das ilustrações. Dada a quantidade vultosa de imagens, é de se esperar que haja diferenças significativas entre as cópias, aspecto que torna esses volumes ainda mais valiosos. Na produção dessas cianotipias, Atkins atuou em parceria com sua amiga Anne Dixon (1799-1877), também fotógrafa que se interessava por botânica. Algumas pranchas são atribuídas a essas duas mulheres. Examinando a proveniências das obras do acervo do Getty Museum, há indícios de que Atkins presenteou Dixon com algumas cianotipias datadas de 1854 (Getty Museum, 2018).

Figura 5. ATKINS, Anna; DIXON, Anne. Aspidium denticulatum, Jamaica. Cianotipia. In: British Algae: Cyanotype Impressions. 1853.

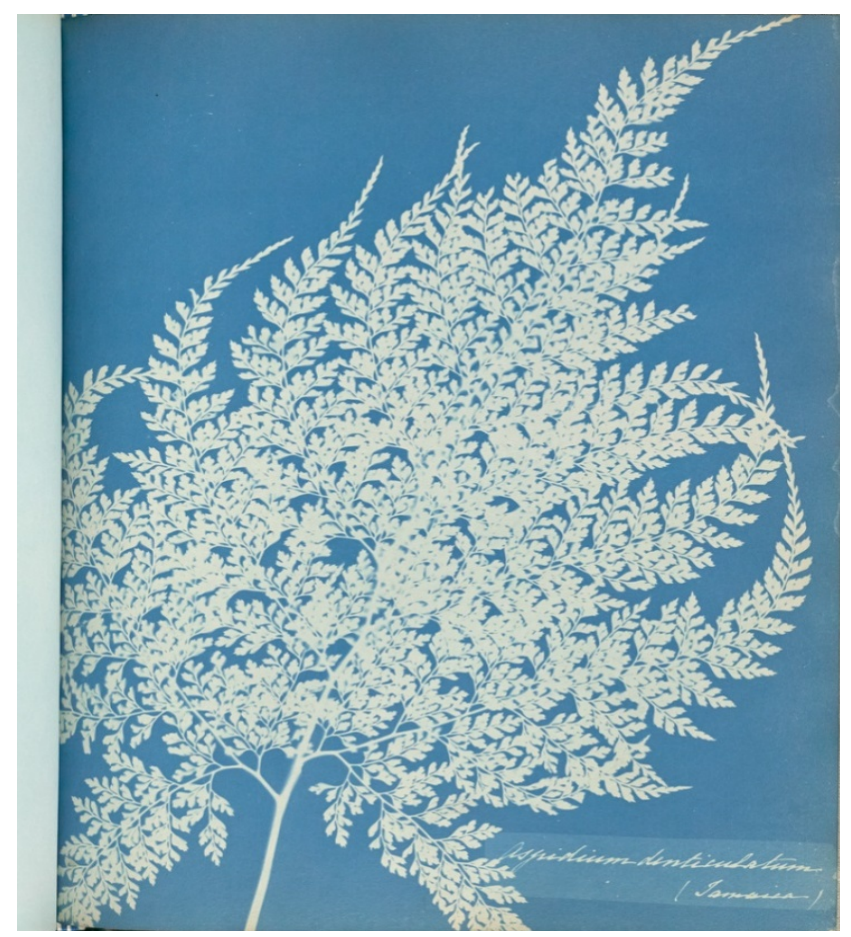

Fonte: Getty Museum. 
Figura 6. ATKINS, Anna. Alaria esculenta. In: British Algae: Cyanotype Impressions. 1843.

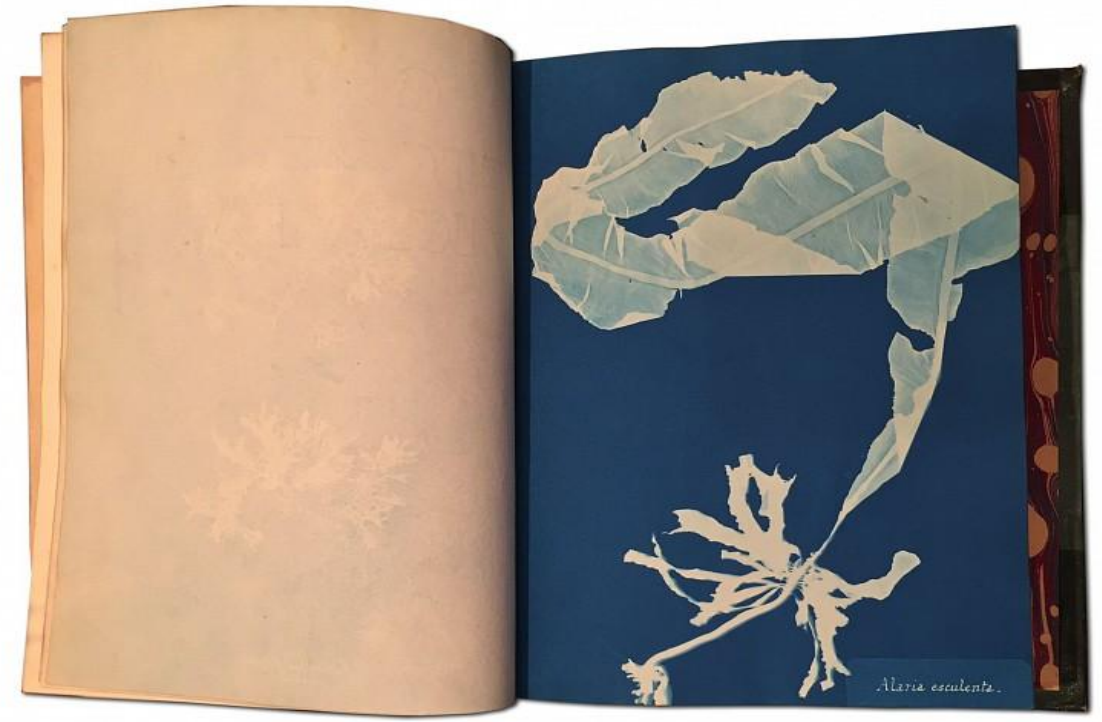

Fonte: https://www.zuckerartbooks.com/exhibition/46/exhibition_works/3190, acesso em: 15 fev. 2019.

Embora se reconheça, na produção de Anna Atkins, o rigor científico, nota-se também uma preocupação estética aliada a um olhar decorativo, aspectos evidentes na maneira como ela arranjava as algas no papel fotográfico. A artista apresenta em suas pranchas as principais características das espécies em composições harmônicas, nas quais as imagens são formadas pelo espectro deixado pelas algas. Essa técnica agregava os modos de representação visual das plantas difundidos pela tradição com um tipo de imagem em que a própria natureza imprime suas características no suporte. $\mathrm{O}$ azul intenso da cianotipia ressalta estruturas, diferentes texturas $e$ padrões das algas. Tais aspectos podem ser associados a uma tradição de representação que visava a evidenciar as principais características da natureza para finalidades de estudo, sem, porém, deixar de produzir imagens com qualidades estéticas.

Nesse sentido, o uso de objetos da naturalia para adornar as casas na Era Vitoriana foi notável. Uma variedade de peças de arte decorativa se apropriou da história natural: arranjos de mesa feitos com plantas secas, flores e frutos de cera ou vidro, mosaicos de papel colorido com temas botânicos, objetos feitos com conchas, entre outras formas de representação da natureza que se podiam encontrar no ambiente privado. Amadores $e$ intelectuais se envolveram na produção desses objetos. Um exemplo desse tipo de arte decorativa associada à história natural pode ser notado no trabalho de Eliza A. Jordson (?), que produziu imagens com algas em guardanapos rendados (Figura 7). O processo de Jordson consistia em colher e fazer arranjos com colagens de algas de diferentes colorações. Jordson presenteou Augustus Graham (1775-1851) com a coleção de guardanapos estampados em reverência aos esforços empreendidos por ele na criação do Brooklyn Apprentice's Library, conhecido atualmente como Brooklyn Museum (Brooklyn Museum, 2019).

Publicações como Sea Mosses: A Collector's Guide and an Introduction to the Study of Marine Algae, escrita pelo botânico A. B. Hervey (1839-1931) e editada em 1881, evidenciam o interesse do público amador pelo estudo das algas. Hervey se ocupou em descrever os métodos de coleta e conservação, as estações do ano mais propícias para a colheita, a classificação das espécies, as metodologias para a secagem e colagem das algas, entre outras informações (Hervey, 1881). Por meio desse exemplo, mais uma vez, pode-se notar o alcance da história natural para além da pesquisa científica, uma vez que atingiu um público que buscava enriquecer seu repertório sobre a natureza e que se interessava esteticamente pelas obras de arte decorativa, em especial pelos objetos da naturalia. 
Figura 7. JORDSON, Eliza A. Algae or seaweed specimen, pasted on colored construction paper, framed by paper lace doilies. The algae have been arranged into designs and scenes. 1948.

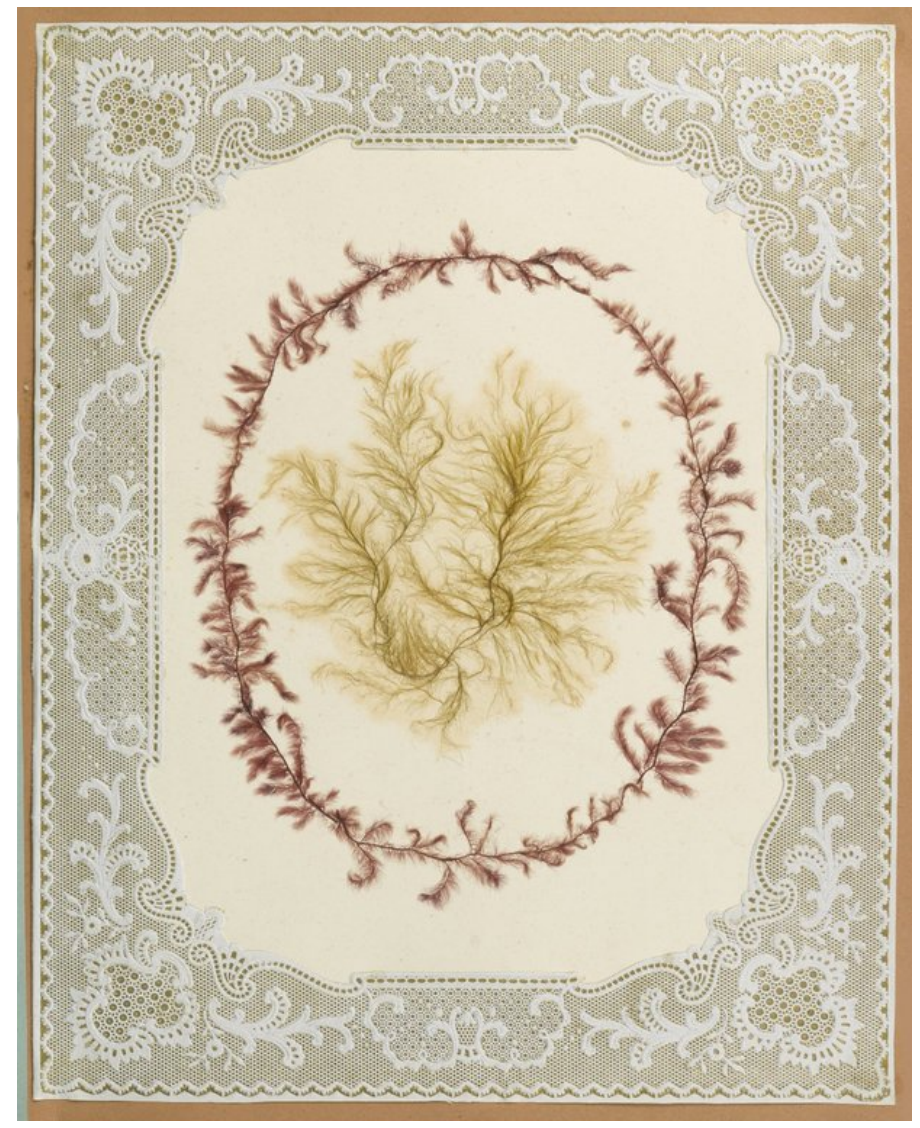

Fonte: Brooklyn Museum Libraries.

O pai de Anna Atkins, John George Children (1777-1852), foi um notável químico, zoólogo, botânico e mineralogista. A partir da convivência próxima com o pai, ela aprendeu lições de botânica, além de produzir aquarelas, desenhos e litografias para ilustrar publicações de história natural. Atkins participou, por exemplo, da publicação inglesa da obra de Jean Baptiste de Lamarck (1744-1829), produzindo 256 desenhos que evidenciam sua habilidade artística e rigor científico (Figuras 8 e 9). Assim como Graham, Atkins estava inserida em um círculo social privilegiado, o que a permitiu ter contato com as descobertas mais recentes da ciência e a trabalhar como ilustradora, apesar das dificuldades enfrentadas pelas mulheres para assumir posições de destaque na ciência. Além da Cyanotype Impressions de Atkins ter sido a primeira obra reproduzida por métodos fotográficos, a publicação também contribuiu para o mapeamento e o estudo das espécies de algas da Inglaterra (Natural History Museum, 2019). 
Figura 8. ATKINS, Anna. Plate V. Vol. XVI. In: LAMARCK, Jean Baptiste, Genera of Shells, 1823.

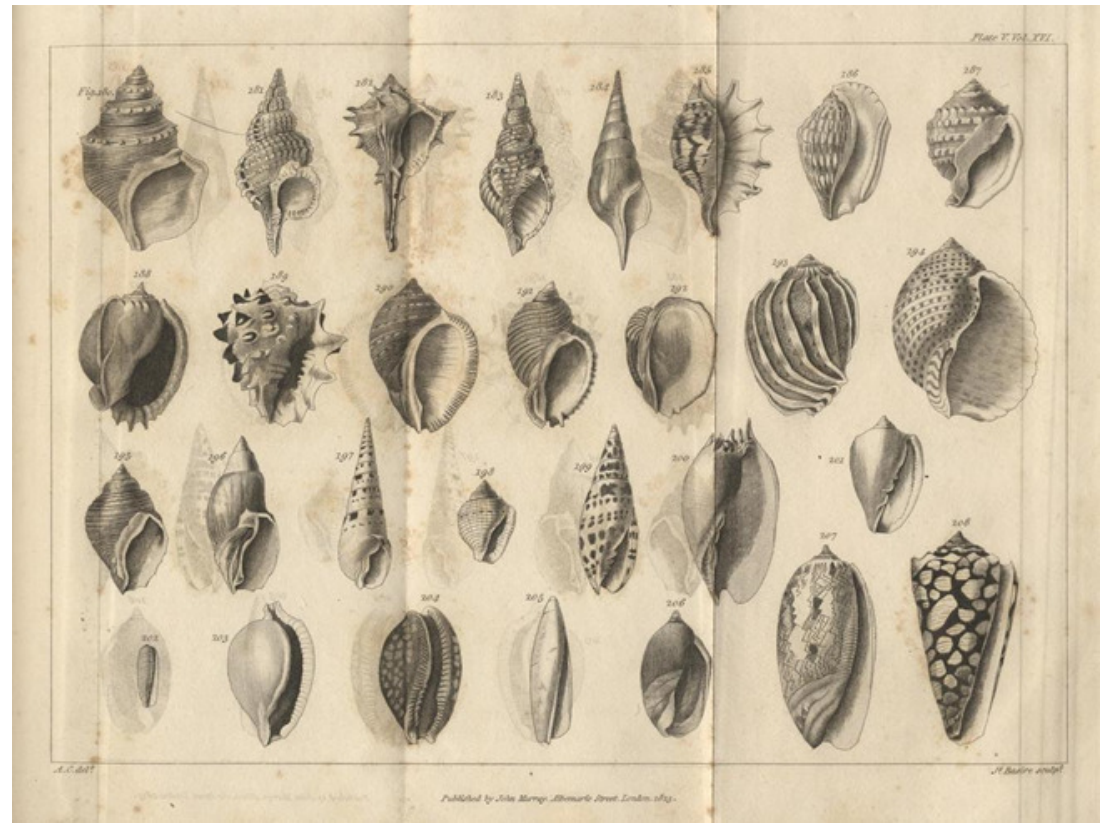

As imagens produzidas por Atkins para os livros de Lamarck evidenciam seu sólido conhecimento de história natural e sua apurada técnica, resultados de anos de dedicação ao estudo $e$ à representação da natureza. A obra de Atkins é extensa e contempla paisagens e ilustrações botânicas. Além disso, ela reuniu uma coleção de algas, formada por mil e quinhentos espécimes, colhidas durante o longo período de produção de seu livro. Essa coleção foi doada ao British Museum, em 1865 (Schaaf, 1979).

Pouco se sabe da formação acadêmica de Anna Atkins, visto que um número reduzido de mulheres ingressou nas instituições e teve seus trabalhos publicados no período. No contexto britânico, a primeira mulher a ingressar na Royal Society foi Mary Somerville (1780-1872), que conseguiu ter sua pesquisa sobre o magnetismo reconhecida e publicada em 1825. Tamanho foi o reconhecimento dos trabalhos de Somerville, que ela recebeu uma medalha de prata pela pesquisa Physical Geography, editada em dois volumes em 1848 (Encyclopedia Britannica, 2019). De toda forma, é necessário pontuar que o caso dessa cientista é uma exceção e que mesmo que algumas mulheres tenham alcançado êxito no reconhecimento de suas pesquisas científicas, a maioria não chegou a ocupar posições de destaque. Mesmo frente a esses entraves, em 1839, Atkins ingressou na Botanical Society, uma das poucas instituições científicas a permitir a presença formal de mulheres. Semelhante a Maria Graham, Atkins construiu sua carreira por meio da articulação com círculos sociais de eruditos. Como mencionado acima, Atkins entrou em contato com a história natural a partir da convivência próxima com o trabalho de seu pai, George Children, que trabalhou no departamento de geologia do British Museum e foi membro da Royal Society (The Royal Society, 2019). 
Figura 9. ATKINS, Anna. Giant clam for the English translation of Lamarck's Genera of Shells, c1820.

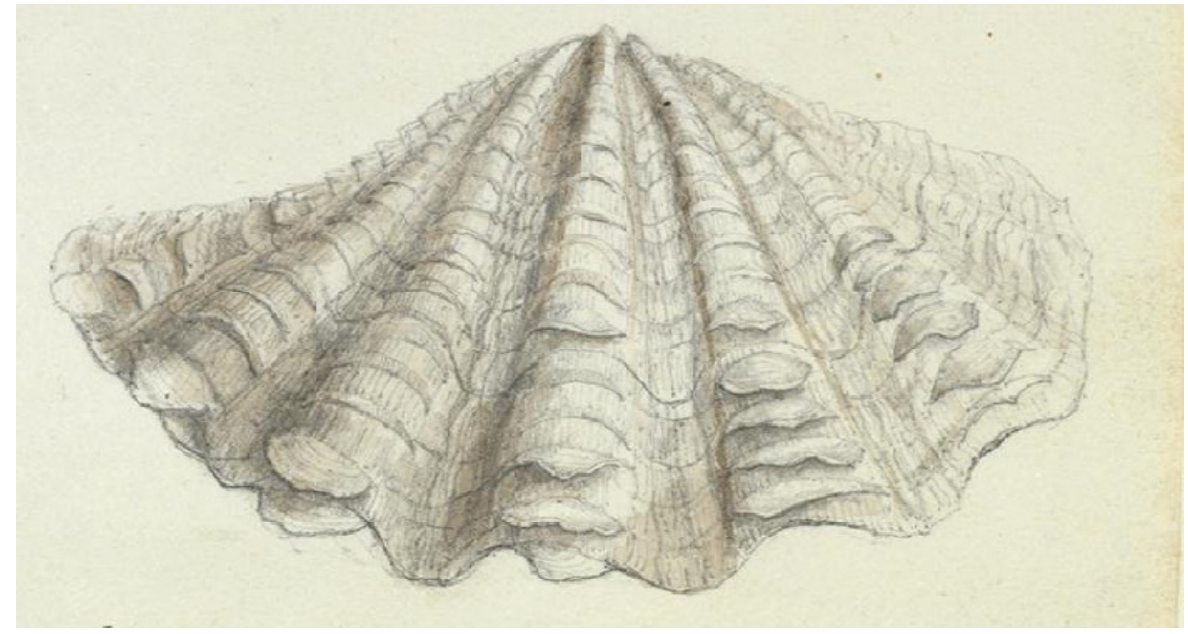

Fonte: Natural History Museum's Library.

Além do contato com a ciência, por intermédio do pai, Atkins conheceu os pioneiros dos experimentos fotográficos e dois grandes expoentes europeus desse novo meio de representação, como Sir John Herschel (1792-1871) e William Henry Fox-Talbot (1800-1877). Atkins enviou algumas cópias do livro British Algae para Talbot, como destaca Schaaf (1979:216):

[...] os contatos iniciais dela com Talbot foram por intermédio de seu pai, mas o relacionamento logo mudou-se para comunicação direta. Atkins deu a Talbot (que, além disso, estava interessado pela Botânica) uma cópia da primeira parte de British Algae [Algas Britânicas] e Talbot lhe deu, em troca, pelo menos uma parte do Pencil of Nature [O Lápis da Natureza]. Vinte anos depois, no artigo "On photography Without the use of Silver" [Sobre fotografia sem o uso da prata], Talbot referiu-se ao processo de cianotipia de Herschel, citando o exemplo da "dama que, há alguns anos atrás, fotografou a série inteira das algas britânicas e, com a maior gentileza e liberalidade, distribuiu as cópias para pessoas interessadas em botânica e fotografia" (Schaaf, 1975:216, tradução nossa) ${ }^{11}$.

Como se observa no excerto acima, Talbot presenteou Atkins com parte das imagens que compõe a obra Pencil of Nature, editada em 1846. Essa publicação é formada por vinte e quatro fotografias acompanhadas de pequenos textos explicativos, além de uma introdução às técnicas fotográficas inventadas pelo autor. O livro de Talbot é formado por uma variedade de fotografias, dentre as quais figuram paisagens, retratos, objetos domésticos, monumentos arquitetônicos $e$ plantas. Sendo o efeito das imagens das plantas do livro de Talbot semelhante ao das cianotipias de Atkins, a vantagem dessa técnica em relação ao método fotográfico empregado por Talbot, que utilizava sais de prata, estava na praticidade da execução e no baixo custo da tiragem (Daston; Galison, 2007; Schaaf, 1979).

Como mencionado acima, os experimentos fotográficos produziram mudanças nas imagens das publicações científicas. Naturalistas da segunda metade do século XIX notaram que um dos principais diferenciais da fotografia era a capacidade de registrar os fenômenos da natureza com uma riqueza de detalhes não alcançada por técnicas tradicionais de reprodução das imagens como litografia, calcogravura e xilogravura. Deve-se, no entanto, lembrar que a reprodução da imagem fotográfica nas publicações continuava dependendo da gravura até meados de 1880, ou seja, a

\footnotetext{
11 "[...] her early contact with Talbot was through her father, but the relationship soon changed to one of direct communication. Atkins gave Talbot (who was additionally interested in botany) a copy of the first part of British Algae and Talbot reciprocated with at least one part of Pencil of Nature. Twenty years later, in the article 'On photography Without the use of Silver', Talbot referred to Herschel's cyanotype process by citing the example that 'a lady, some years ago, photographed the entire series of British seaweeds, and most kindly and liberally distributed the copies to persons interested in botany and photography"”(Schaaf, 1975:216).
} 
fotografia era usada como esboço para, então, ser gravada em uma matriz, de onde se produzia uma tiragem (Daston; Galison, 2007).

Como auxiliar das imagens científicas, a fotografia se notabilizou pela "objetividade", já que muitos a consideravam isenta de interpretação do artista. Isso, certamente, colaborou com a difusão das técnicas fotográficas para as mais diferentes finalidades, em especial para os registros dos grupos humanos. Isso porque as convenções acadêmicas dos artistas induziam distorções nos tipos humanos não europeus, fato que colaborou para que a fotografia fosse extensamente adotada para os registros etnográficos (Daston; Galison, 2007).

Para além da representação visual da natureza, os métodos fotográficos foram utilizados pela ciência de diferentes modos. A ilustradora e botânica Priscilla Susan Bury (1799-1872) construiu protótipos de organismos unicelulares observados pelo microscópio. Esses protótipos eram fotografados e apresentados como se fossem imagens tiradas diretamente dos seres vivos. A obra ilustrada por Bury ${ }^{12}$, Polycystins, figures of remarkable forms \&c. in the Barbados chalk deposit, foi editada em 1862 e está inserida em um contexto de publicações das áreas de Astronomia e Geografia, que usavam métodos semelhantes de ilustração. Jardine (2014) destacou que "geralmente, não deveria nos surpreender que, quando a fatura da imagem envolve o uso de tecnologia complexa e avançada, a relação entre noções de objetividade e representação não mediada da natureza torna-se altamente complicada"13 (Jardine, 2016:26, tradução nossa). Significa dizer que aparatos tecnológicos como o microscópio e a fotografia conferiam um grau maior de fidelidade na reprodução da natureza em comparação aos meios tradicionais empregados na ilustração das publicações científicas, os quais dependiam da habilidade manual e da capacidade de observação da natureza operadas pelos artistas em parceria com naturalistas (Jardine, 2014; Daston; Galison, 2007).

Figura 10. Exposição Blue Prints: The Pioneering Photographs of Anna Atkins. The New York Public Library, 2019.

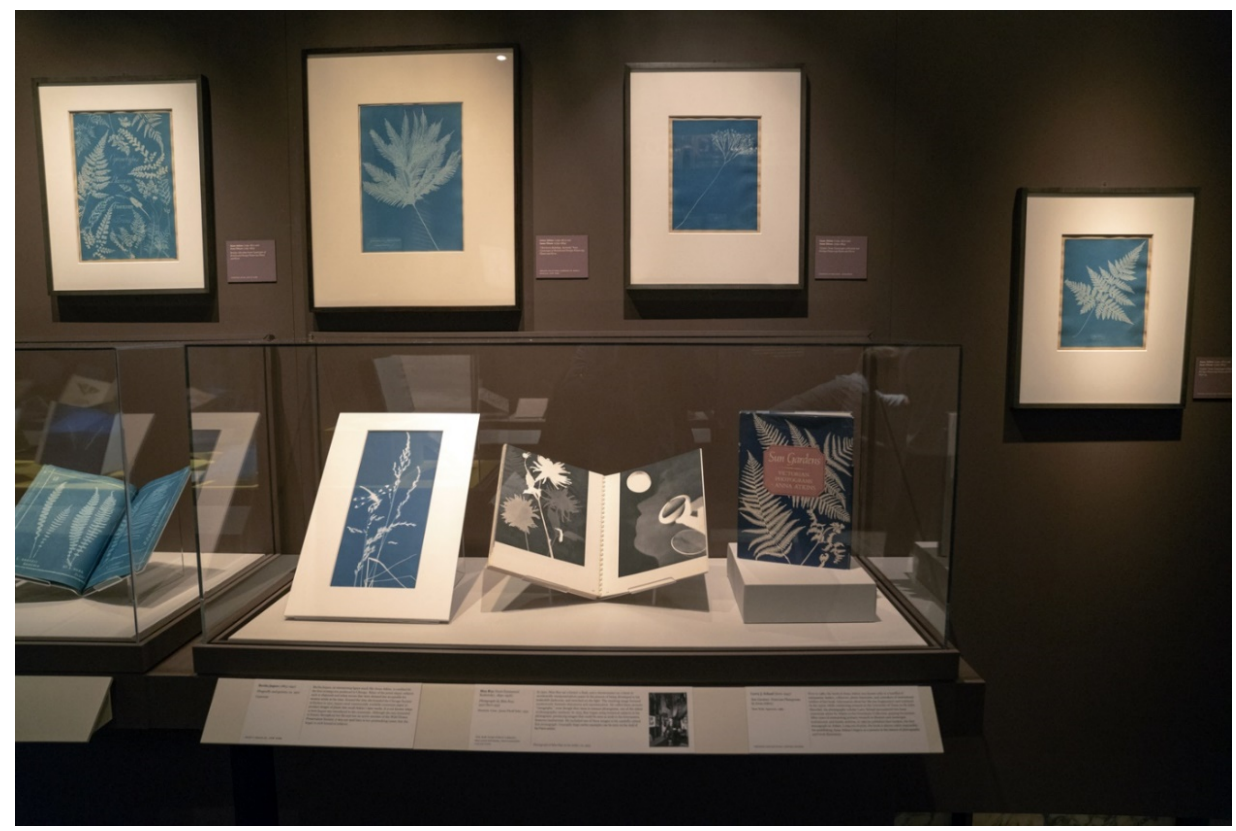

Embora poucas pesquisas tenham se ocupado do trabalho pioneiro de Atkins com o uso de técnicas fotográficas na ciência, existem alguns movimentos para compreender e viabilizar o legado dessa artista. Recentemente, entre o final de 2018 e início de 2019, ocorreu, na National Public

\footnotetext{
${ }^{12}$ Priscilla Bury participou de outras publicações como Drawings of lilies, de 1829, e A Selection of Hexandrian Plants, editada entre 1831 e 1834 (Science Museum Group, 2019).

13 "More generally, it should not surprise us that, when image-making involves the use of complex high technologies, the relationship between notions of objectivity and the unmediated depiction of nature becomes as highly complicated" (Jardine, 2016:26).
} 
Library de Nova Iorque, uma exposição sobre a produção dessa artista. Sob o título, Blue Prints: The Pioneering Photographs of Anna Atkins, a extensa obra de Atkins foi mostrada no contexto da segunda metade do século XIX em que se observou intensa experimentação com as diversas possibilidades visuais proporcionadas pelas técnicas fotográficas. Essa exposição trouxe ao público diferentes aspectos da cianotipia, incluindo registros científicos da natureza, as particularidades da técnica, os efeitos visuais e a beleza das imagens impressas (Figura 10).

Curtis's Botanical Magazine e os métodos de reprodução manual das imagens nas publicações científicas: algumas considerações

Após a adoção da fotografia como parte do método de ilustração, alguns periódicos mantiveram a produção manual das imagens. Esse foi o caso do Curtis's Botanical Magazine. Criado em 1787 e ativo até hoje, esse periódico se notabilizou por editar ilustrações coloridas das mais diversas plantas com a finalidade de divulgar os conhecimentos de botânica para um vasto público ${ }^{14}$. Matilda Smith foi uma das principais ilustradoras botânicas a contribuir com o Curtis' Botanical Magazine. Ela colaborou com o periódico por 45 anos, durante os quais mapeou espécies pouco conhecidas da flora australiana. Smith também é lembrada por ter sido uma das primeiras mulheres a ingressar na Linnean Societye por ter alcançado o posto de principal ilustradora do Kew Gardens, em 1898 (Victorian University of Wellington, 2018; Parker; Ros-Jones, 2013).

As publicações de história natural cresceram a partir do final do século XVIII, e um dos modelos de representação das plantas mais difundidos entre o público britânico foi fornecido pela obra do botânico William Curtis (1746-1799) ${ }^{15}$, fundador da revista acima mencionada. Após a morte de Curtis, a edição desse periódico passou a ser chefiada por dois destacados diretores do Kew Gardens. William Hooker e, posteriormente, Joseph Dalton Hooker (1817-1911) (Curtis's Botanical Magazine, 1807; Nickelsen, 2006).

Matilda Smith foi instruída no Kew Gardens, onde aprendeu a arte da ilustração botânica com seu primo Joseph Hooker, que era um hábil desenhista. Entre 1878 e 1920, ela produziu 2300 pranchas para o Curtis's Botanical Magazine, ficando responsável por quase toda as ilustrações das edições. Além de ter colaborado intensamente com esse periódico, Smith produziu imagens para as seguintes publicações: Icones Plantarum (1886-1887), de Joseph Hooker, e The Wild and Cultivated Cotton Plants of the World (1907), de Sir George Watt (1851-1930) (Victorian University of Wellington, 2018).

Tomando as ilustrações da planta Titian arum (Figuras 11 e 12), Amorphophalus titianus, que foi registrada por Smith para o Curtis's Botanical Magazine, em 1889, podemos tratar de aspectos da produção editorial desse periódico. A planta retratada pela artista é conhecida pela exuberância de sua flor, que pode alcançar 2,5 metros, e por exalar um odor característico, que lembra o de um corpo em decomposição. Smith ilustrou a primeira floração da Titian arum, no Kew Gardens, e, enquanto produzia uma série de registros do desabrochar da exuberante flor, diz-se que a artista chegou a passar mal por causa do forte cheiro. Isso porque o nível de precisão exigido pelo periódico demandava dos artistas inúmeras horas de observação do espécime vivo para manter a representação da natureza o mais fiel possível. Para tanto, a coloração das gravuras continuava sendo feita à mão, e era essencial se ater à precisão das estruturas das plantas em seus mais diversos estágios de crescimento (Parker; Ros-Jones, 2013).

\footnotetext{
14 " $A$ work intended for the use of such ladies, gentleman, gardeners, as wish to become scientifically acquaited with the plants they cultivated' (Curtis's Botanical Magazine, 1807).

${ }^{15} \mathrm{Na}$ obra ilustrada de Curtis Flora Londinensis, de 1777, a representação das plantas recorre a uma série de recursos para mostrar simultaneamente diferentes ângulos e estágios de crescimento das plantas. Ainda que esse tipo de imagem partisse da observação da natureza, havia uma sistematização dos elementos para fornecer informações sobre as espécies retratadas (Nickelsen, 2006).
} 
Figuras 11 e 12. Smith, Matilda. Amorphophalus titianus.
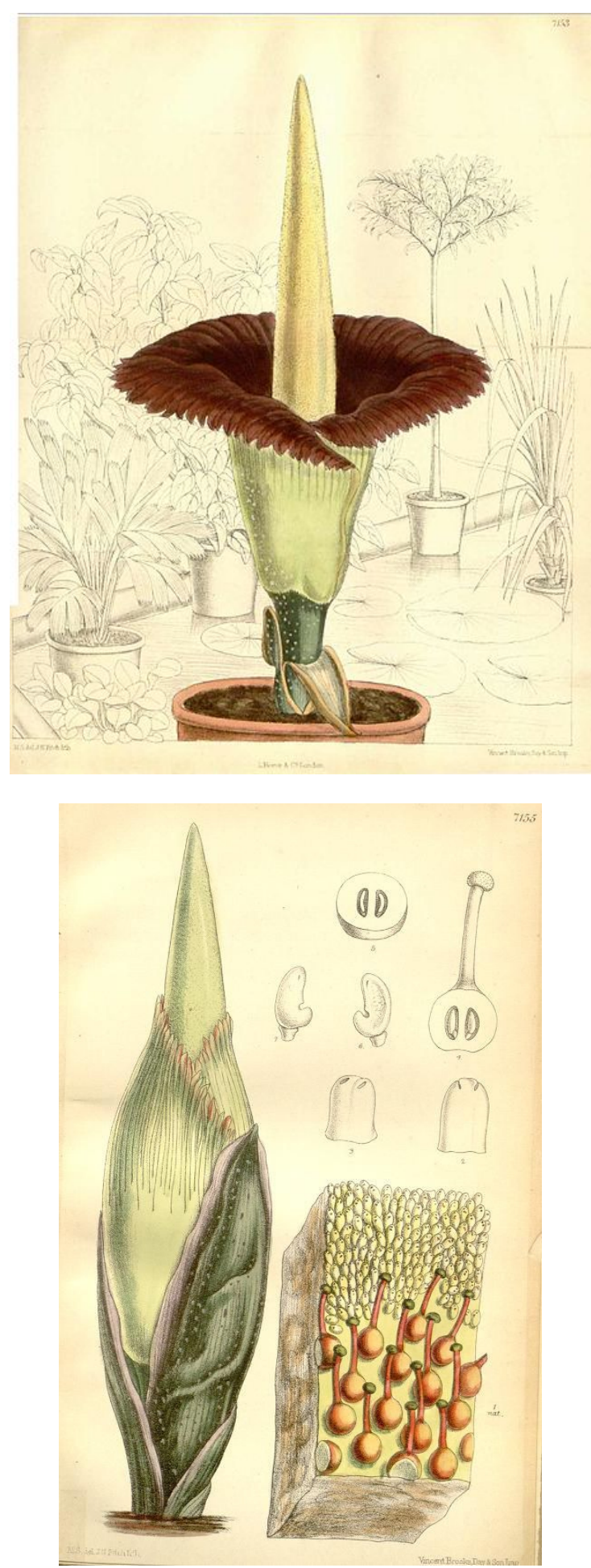

Fonte: Curtis's Botanic Magazine, 1889.

Para fins de representação da natureza, os botânicos davam mais importância ao desenho do que à cor. Não que o colorido estivesse fora da preocupação dos pesquisadores. Ao contrário, as tonalidades e matizes eram tratados com o mesmo grau de rigor do desenho. Contudo, a representação linear era tida como mais eficiente para identificação das plantas. A aplicação manual da cor nas ilustrações botânicas permaneceu como parte do método de produção das imagens da Curtis's Botanical Magazine desde a sua inauguração até 1949, ou seja, perdurou por quase duzentos anos. Mesmo a litografia fornecendo cópias coloridas das imagens, a aplicação manual da aquarela nas matrizes das gravuras era tida pelos editores como um método mais preciso. Esses 
aspectos evidenciam o cuidado desse periódico com a coloração das gravuras que, na percepção dos editores, só poderia ser alcançada com a aplicação manual dos pigmentos (Barnes; Simpson, 2008).

No período em que Matilda Smith produziu ilustrações para o Curtis's Botanical Magazine, a fotografia já havia se firmado na produção dos periódicos ilustrados.

Por volta de meados do século XIX, o jornalismo horticultural estava florescendo na Inglaterra, com revistas, jornais tais como The Gardeners' Chonicles, The Garden e Amateur Gardening que provia jardineiros, seus empregados e um número crescente de jardineiros amadores. Fotógrafos de vistas de jardins e retratos de plantas acrescentavam imensamente tanto à comunicação da informação quanto ao apelo das descrições escritas que as acompanhavam e, como bem documentado, a introdução de Country Life, em 1897, levou a fotografia de jardinagem a novas alturas (Sewell, 2014:92, tradução nossa) ${ }^{16}$.

A reprodução em preto e branco da fotografia era utilizada nas revistas dedicadas à botânica, à jardinagem e à horticultura no início do século XX. Entretanto, essas reproduções eram de baixa qualidade, e a produção colorida das imagens ainda estava em fase de experimentação (Sewell, 2014).

Os custos com a produção de livros ilustrados com gravuras coloridas à mão eram consideravelmente elevados, pois a cadeia produtiva envolvia inúmeros profissionais capacitados que, em geral, tinham seus trabalhos supervisionados de perto pelos naturalistas. Por uma série de motivos, não era possível estabelecer um padrão cromático para a pigmentação manual das ilustrações. Uma das razões para isso era a dificuldade para encontrar pigmentos semelhantes, o que acabava impedindo o estabelecimento de tabelas cromáticas para guiar os artistas. Em decorrência disso, as ilustrações coloridas variavam muito de livro para livro. Alguns cuidados, entretanto, eram indispensáveis nesse processo de aplicação dos pigmentos. Era necessário diluir a tinta de modo a deixar à mostra as linhas da gravura, essenciais para o reconhecimento das plantas. Além disso, as misturas eram calculadas para que os pigmentos pudessem ser reconhecíveis entre si. Era, também, usual entre artistas usar desenhos feitos pelos naturalistas como parâmetros para obter edições mais uniformes das pranchas ilustradas. Em suma, todos esses aspectos, necessariamente, encareciam esse tipo de edição (Nickelsen, 2006).

Tomando como exemplo a obra Flora Londinensis: or Plates and Descriptions of such plants as grow wild in the Environs of London, editada por William Curtis, podemos observar aspectos da produção ilustrada do periódico Curtis's Botanical Magazine. Ilustrada com gravuras em metal coloridas à mão, a Flora Londinensis foi editada em seis fascículos distribuídos em dois volumes e impressos em formato de fólio, publicadas entre 1777 e 1798. Juntos, os seis fascículos contêm cerca de 432 ilustrações, em média um total de 72 imagens em cada livro. Para se ter uma noção do trabalho necessário para editar esse tipo de livro, Curtis contratou trinta artistas, dentre os quais homens e mulheres que atuavam somente na coloração das imagens e que trabalhavam sob o olhar atento do botânico. Outra dificuldade enfrentada para a editoração de livros com ilustrações coloridas à mão era a escassez de profissionais que possuíssem um olhar atento e treinado para representar as cores da natureza. Além de tudo, o trabalho de coloração exigia concentração e expertise do artista, aspectos essenciais considerando-se as longas horas de trabalho. Segundo Nickelsen (2006:62):

Geralmente, colorir as pranchas era responsabilidade do editor [...], que também tinha de cobrir as despesas por esse trabalho, bem como pela fatura das placas de cobre; se, ao final, ele conseguiria ou não reembolsar todos esses gastos, dependia, substancialmente, em quão bem as impressões vendiam. E, assim, poucos editores poderiam arcar com a contratação de

\footnotetext{
16 "By the mid-nineteenth century, horticultural journalism was flourishing in Britain, with magazines and newspapers such as The Gardeners'Chronicles, The Garden and Amateur Gardening catering for professional gerdeners, their employers and the rising number of amateur gardeners. Photographs of garden views and plant portraits added greatly to both the communication of information and the appeal of the written descriptions they accompanied and, as well documented, the introduction of Country Life in 1897 took garden photography to new Heights" (Sewell, 2014:92-93).
} 
especialistas bem treinados para colorir a mão suas gravuras, além de empregar gravadores em cobre qualificados (Nickelsen, 2006:62, tradução nossa) ${ }^{17}$.

A literatura mostra que muitas mulheres participaram da coloração das ilustrações de publicações científicas de destaque. Harriet Anne Thiselton-Dyer (1859-1945), por exemplo, trabalhou como desenhista e colorista de estampas na Curtis's Botanical Magazine. Esse trabalho era mal remunerado e menos reconhecido, além de ser uma ocupação fatigante, haja vista a quantidade de ilustrações $e$ as exigências dos editores para as gravuras coloridas manualmente. Além de tudo, a coloração das gravuras exigia habilidade manual e um olho treinado para a aplicação dos pigmentos para, assim, fornecer edições uniformes das imagens. Há, porém, algumas citações ao trabalho dessas mulheres nas edições do Curtis's Botanical Magazine, fato que evidencia algum reconhecimento público de seus trabalhos. William Turner Thiselton-Dyer (1843-1928) dedicou o volume de 1905 do mencionado periódico à sua mulher Harriet, destacando a habilidade da artista na produção de inúmeras ilustrações (Thiselton-Dyer, 1905; Daston; Galison, 2007).

Outro aspecto que se destaca na produção ilustrada da segunda metade do século XIX e início do século XX é o uso da fotografia no processo de criação das ilustrações. A segunda floração da planta Titian arum foi registrada em 1901 por uma série de quatro fotografias que mostra estágios da floração da planta no Kew Gardens (Figura 13). Essa planta atraía atenção dos botânicos e do público em geral por se tratar de uma espécie exótica e recém-chegada à Londres, além das qualidades mencionadas acima quando tratamos da primeira floração da Titian arum, registrada por Matilda Smith (Figuras 11 e 12). Notemos que essa série de fotografias evidencia etapas específicas da floração da Titian arum e são imagens que seguem metodologia semelhante à adotada pelos registros feitos por meio do desenho.

Figura 13. Amorphophallus titanium flowering, 1901.

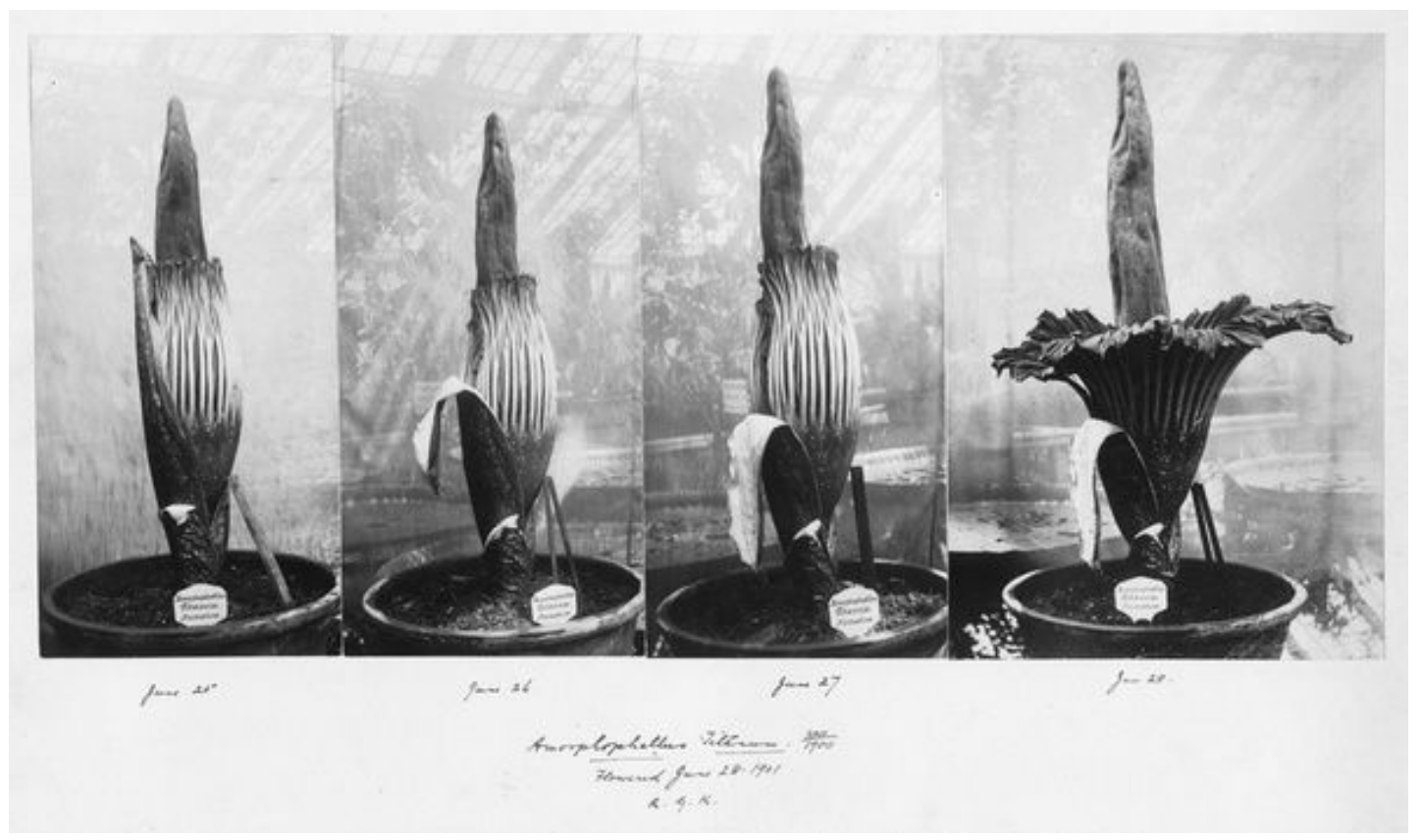

Fonte: Royal Botanic Gardens.

Até o momento, não foram encontradas informações sobre a metodologia usada por Matilda Smith nas ilustrações da Curtis's Botanical Magazine, porém, a partir dos relatos de outros artistas, podemos supor que a fotografia era usada como parte do processo de produção das imagens. Uma

\footnotetext{
17 "Generally, the colouring of the plates was the responsibility of the publisher [...], who also had to cover the expenses for this work as well as for the making of the copperplates; whether he would be able to make up for this expenditure in the end depended substantially on how well the prints sold. And so, few publishers could afford to employ well-trained specialists to hand-colour their engravings, in addition to engaging qualified copperplate engravers" (Nickelsen, 2006:62).
} 
série de cartas trocadas entre os editores da Curtis's Botanical Magazine e coletores de plantas mostra que o uso das fotografias fazia parte do procedimento adotado pelos profissionais envolvidos na produção desse periódico ilustrado. Muitas vezes, coletores enviavam fotografias das plantas junto de desenhos coloridos feitos a partir da observação da natureza (Kew Archive Catalogue, 2019).

Essa metodologia mostra que a fotografia passou a ser um meio que auxiliava ilustradores $e$ botânicos, mas que ainda era corrente no meio editorial a observação direta dos fenômenos. Isso porque a fotografia surgiu quando a ilustração científica se firmava metodologicamente a partir da colaboração entre desenhista e naturalista, período em que o desenho estava se estabelecendo como um processo intelectual no qual a escolha dos elementos da natureza a serem representados $e$ o modo como organizá-los na composição eram essenciais para as ilustrações das publicações científicas (Daston; Galison, 2007).

No que se refere ao reconhecimento público dessas mulheres artistas, algumas se destacaram e chegaram a receber medalhas e alcançar altos cargos como ilustradoras e naturalistas. $\mathrm{O}$ trabalho de Matilda Smith se projetou publicamente a partir do momento em que ela assumiu o posto de primeira ilustradora do Curtis's Botanical Magazine, em 1898. Antes disso, ela estava subordinada a seu primo, Joseph Hooker. Após se firmar na carreira, Smith foi eleita presidente da KEW Guild ${ }^{18}$, em 1916, e foi a segunda mulher a ser aceita na Linean Society. Arquivos do Kew Gardens mostram o nome da artista na folha de pagamento da Curtis's Botanical Magazine. Ademais, documentos indicam que, em julho de 1927, ela recebeu postumamente um prêmio da Royal Horticultural Society, cujo valor foi doado ao Kew Guild para contribuir para a formação de jovens horticultores. Outra homenagem concedida a Smith foi a medalha Veitch ${ }^{19}$, em reconhecimento ao seu extenso trabalho como ilustradora botânica (Kew's Archive Catalogue, Matilda Smith Memorial, 1927-1933).

A produção de Maria Graham, Anna Atkins e Matilda Smith evidencia percursos de mulheres que contribuíram de diferentes modos para a produção científica ilustrada. Embora se reconheça a importância dessas artistas, ainda são escassas as pesquisas que estudem suas trajetórias e que tratem de suas produções visuais e escritas. Especialmente no caso de Atkins e de Smith há pouca bibliografia. Ambas deixaram coleções naturais, notações botânicas, ilustrações publicadas em livros e periódicos de grande circulação, bem como coleções em museus como o Royal Botanic Gardens, British Museum e o Brooklyn Museum. Nesse sentido, discutir aspectos da produção dessas artistas pode contribuir para a história da presença das mulheres na ciência, além de divulgar produções ainda periféricas ${ }^{20}$.

Assim sendo, a participação delas na produção de conhecimento científico não pode ser dissociada de suas contribuições para a divulgação da ciência, seja pela produção ilustrada com métodos tradicionais de reprodução de imagens, seja por meio do uso da fotografia. Falar de uma história da botânica implica falar de uma história das ilustradoras. Na oscilação das fronteiras entre arte e ciência, residem aspectos essenciais para compreensão das ilustrações das publicações científicas do século XIX.

\footnotetext{
${ }^{18}$ Associação ligada ao Royal Botanic Gardens (KEW Gardens) que se ocupa com o fomento de pesquisas nas áreas de Botânica, Micologia e Horticultura (Kew Guild, 2019).

${ }^{19} \mathrm{~A}$ medalha Veitch é uma premiação que homenageia personalidades que contribuíram com a ciência e com a horticultura (Royal Horticultural Society, 2019).

${ }^{20}$ Embora as discussões que perpassam o papel das mulheres nos campos artísticos e científicos no início do século XIX sejam anteriores às disputas teóricas que fundaram o amplo campo interdisciplinar dos estudos gênero, lembramos que as noções de gênero partem de pressupostos sociais e relacionais, abarcando diversos significados a depender da sociedade e do contexto histórico. Para Joan Scott, a categoria "gênero" abarca as construções culturais instituídas a um corpo sexualizado, levando em consideração que as relações entre os sexos são sociais: "(1) o gênero é um elemento constitutivo de relações sociais baseadas nas diferenças percebidas entre os sexos e (2) o gênero é uma forma primária de dar significado às relações de poder" (Scott, 1995:86). A autora enfatiza que o termo gênero não estaria restrito às oposições entre homens e mulheres, mas deveria ser pensado a partir de um sistema relacional, não-binário e segundo pressupostos históricos. Assim, as atuais discussões de gênero possibilitam entrever as ambiguidades e complexidades que modelaram os lugares sociais das mulheres cientistas $e$ artistas nos oitocentos, especialmente no trânsito de valores estéticos e morais entre a Europa Ocidental e o Brasil.
} 


\section{Referências bibliográficas}

AKEL, Regina. Maria Graham: a literary biography. New York, Cambria Pess, 2009.

AMARANTE, Maria Inês. Flora Tristan: jornalismo militante em tempo de revoltas. Rev. Katál v. 13 n. 1 , Florianópolis, jan./jun. 2010, pp.110-118.

BELL, Bill; KEIGHREN, Innes M.; WITHERS, W.J. Travels into Print: Exploration, Writing, and publishing with John Murray, 1773-1859. Chicago and London, The University of Chicago Press, 2015.

DASTON, Lorraine; GALISON, Peter. Objectivity. New York, Zone Books, 2007.

GRAHAM, Maria. Diário de uma viagem ao Brasil. Itatiaia, Belo Horizonte. Editora da Universidade de São Paulo, São Paulo, 1990.

Journal of a Voyage to Brazil, and residence there, during the years 1821, 1822, 1823. London, John Murray Press, 1824a.

Journal of a residence in Chile, during the year 1822and a voyage from Chile to Brazil in 1823. London, John Murray Press, 1824b.

Letters on India Journal of a Residence in India, second edition; Edinburgh, A. Constable and Co.; London, Longman, Hurst, Rees, Orme, and Brown, 1814.

GONÇALVES, Margaret de Almeida. Livros de viagem do Oitocentos e a fabricação do Oriente: a Índia e a escrita em Maria Graham. Topoiv. 12, n. 22, jan.-jun. 2011, pp.96-117.

Artifício e excesso: narrativa de viagem e a visão sobre as mulheres em Portugal e Brasil. Revista Estudos Feministas 13(3), Florianópolis, setembro-dezembro, 2005, pp.613-627.

HAGGLUND, Betty. The Botanical Writings of Maria Graham. Journal of Literature and Science v. 4, n. 1, 2011.

HERVEY, A. B. Sea Mosses: a collection guide and an introduction to the study of marine algae. Boston, Estes and Laurian,1988.

JARDINE, Boris. Made real: artifice and accuracy in Nineteenth-Century scientific illustration. Science Museum Group Journal, 2014.

LEITE, Miriam Lifchtz Moreira. Mulheres viajantes no século XIX. cadernos pagu (15), Campinas-SP, Núcleo de Estudos de Gênero-Pagu/Unicamp, 2000, pp.129-143.

MARTINS, Luciana. O Rio de Janeiro dos viajantes: O olhar Britânico, 1800-1850. Jorge Zahar, Rio de Janeiro, 2001.

MATTOS, Claudia Valladão de. Winckelmann e o meio antiquário de seu tempo. Revista de História da Arte e Arqueologia n. 9, jan-jun 2008, pp.69-79.

A pintura de paisagem entre arte e ciência: Goethe, Hackert, Humboldt. TERCEIRA MARGEM: Revista do Programa de Pós-Graduação em Ciência da Literatura, Universidade Federal do Rio de Janeiro, Centro de Letras e Artes, Faculdade de Letras, Pós-Graduação, Ano IX, n. 10, 2004, pp. 152169.

PALMER, Caroline, Maria Callcott on Poussin, Painting, and the Primitives I19: Interdisciplinary Studies in the Long Nineteenth Century, 28, 2019.

"I Will Tell Nothing that I Did Not See": British Women's Travel Writing, Art and the Science of Connoisseurship, 1776-1860. Forum for Modern Language Studies v. 51, n. 3, June, 2015, pp.248-268.

PARKER, Lynn; ROSS-JONES, Kiri. The story of Kew Gardens in Photographs. London, Arcturus, 2013.

PEIXOTO, Ariane Luna; FILGUEIRAS, Tarciso de Sousa. Maria Graham: anotações sobre a flora do Brasil. Acta bot. bras. 22(4), 2008, pp.992-998.

RODENAS, Adriana Mendés. Transatlantic Travels to Nineteenth-Century Latin America: European Women Pilgrims. Lewisbugh, Bucknell University Press, 2014.

SANTOS, Márcia Cristina de Oliveira. Maria Graham e a dupla documentação do feminino no Brasil de 1821 a 1823. Uma abordagem discursivo-crítica. Dissertação (Mestrado em Linguística Aplicada), UFRJ, Rio de Janeiro, 2014. 
SCHAAF, L. The First Photographically Printed and Illustrated Book. The Papers of the Bibliographical Society of America 73 (2), 1979, pp.209-224 [http://www.jstor.org/stable/24302456 - acesso em: 03 mai. 2019].

SCHIENBINGER, Londa. The Mind has no Sex?: Women in the Origins of Modern Science. London, Harvard University Press, 1991.

SCOTT, Joan. Gênero: uma categoria útil de análise histórica. Revista Educação \& Realidade, Porto Alegre, Faculdade de Educação UFRGS, jul/dez, 1995, pp.71-99.

SEWELL, P. Miss Ellen Willmott of Warley Place, Essex: Eminent Gardener, Horticulturist and Garden Photographer. Garden History 42(1), 2014. pp.89-105 [http://www.jstor.org/stable/24636288 - acesso em: 03 mai. 2019].

SOUZA, Maria de Fátima Medeiros de. Viajar, observar e registrar: coleção e circulação da produção visual de Maria Graham. Tese (Doutorado em Artes), Instituto de Artes, Universidade de Brasília, Brasília, 2020.

Maria Graham e as suas "vistas" do entorno e da cidade de Roma: estudo de um conjunto de gravuras do acervo do Museu Britânico. 19\&20v. XII, n. 2, Rio de Janeiro, jul./dez. 2017, pp.1-18.

STEPHEN, Leslie. Dictionary of national biography. Vol. VIII. Burton Cantwell Macmillan and Co. London, Smith, Elder, \& Co, 1886.

THISELTON-DYER, Sir Willian Turner (ed.). Curtis's Botanical Magazine. London, Lovell Reeve \& Co, 1905.

THOMPSON, Carl. Sentiment and Scholarship: Hybrid Historiography and Historical Authority in Maria Graham's South American Journals'. Journal Women's Writing v. 24, 2017, pp.185-206.

"Only the Amblyrhynchus": Maria Graham's Scientific Editing of Voyage of HMS Blonde (1826/27). Journal of Literature and Science v. 8, n. 1, 2015, pp.48-68.

Earthquakes and Petticoats: Maria Graham, Geology, and Early Nineteenth-Century 'Polite' Science'. Journal of Victorian Culture v. 17, 2012, pp.329-346.

\section{Fontes}

BRITISH Travel Writing [http://www4.wlv.ac.uk/btw/authors/1091 - acesso em: 16 fev. 2019].

BROOKLYN Museum [https:/www.brooklynmuseum.org/opencollection/collections - acesso em: $23 \mathrm{dez}$. 2019].

CURTI'S Botanical Magazine. London; New York, Academic Press, 1807 [https://www.biodiversitylibrary.org/bibliography/706\#/summary - aesso em: 10 mar. 2018].

GETTY MUSEUM [http://www.getty.edu/art/collection/objects/100758/anna-atkins-and-anne-dixonhymenophyllum-wilsonii-british-british-1853/ - acesso em: 04 nov. 2018].

KEW'S Archive Catalogue. Matilda Smith Memorial, 1927-1933 [http://www.calmview.eu/kew/calmview/Record.aspx?src=CalmView.Catalog\&id=KGU\%2f1\%2f4\%2f7\&p os $=16$ - acesso em: 01 mai. 2019].

KEW'S Archive Catalogue [http://www.calmview.eu/kew/calmview/Overview.aspx - acesso em: 02 mai. 2019].

KEW GUILD [https://kewguild.org.uk/ - acesso em: 05 mai. 2019].

NATURAL History Museum [https://www.nhm.ac.uk/discover/anna-atkins-cyanotypes-the-first-book-ofphotographs.html. Acesso em: 05 dez. 2018.

ROYAL Horticultural Society [https://www.rhs.org.uk/ - acesso em: 03 mai. 2019].

SCIENCE Museum Group [https://collection.sciencemuseum.org.uk/people/ap27970/bury-priscilla-susan acesso em: 04 maio 2019]-.

VICTORIAN University of Wellington, 2018 [http://nzetc.victoria.ac.nz/tm/scholarly/tei-SamEarl-t1-body1-d14d4.html - acesso em: 07 abr. 2018]. 